\title{
Evidence Why Paroxetine Dose Escalation is Not Effective in Major Depressive Disorder: A Randomized Controlled Trial With Assessment of Serotonin Transporter Occupancy
}

\author{
Henricus G Ruhé*,', Jan Booij ${ }^{2}$, Henk C v Weert ${ }^{3}$, Johannes B Reitsma ${ }^{4}$, Eric JF Fransen ${ }^{5}$, Martin C Michel $^{6}$ \\ and Aart $H$ Schene' \\ 'Program for Mood Disorders, Department of Psychiatry, Academic Medical Center, University of Amsterdam, Amsterdam, The Netherlands; \\ ${ }^{2}$ Department of Nuclear Medicine, Academic Medical Center, University of Amsterdam, Amsterdam, The Netherlands; ${ }^{3}$ Department of General \\ Practice, Academic Medical Center, University of Amsterdam, Amsterdam, The Netherlands; ${ }^{4}$ Department of Clinical Epidemiology, Biostatistics \\ and Bioinformatics, Academic Medical Center, University of Amsterdam, Amsterdam, The Netherlands; ${ }^{5}$ Department of Pharmacy and Clinical \\ Pharmacology, Onze Lieve Vrouwe Gasthuis, Amsterdam, The Netherlands; ' Department of Pharmacology and Pharmacotherapy, Academic \\ Medical Center, University of Amsterdam, Amsterdam, The Netherlands
}

\begin{abstract}
Dose escalation is often used in depressed patients who fail to respond to standard doses of selective serotonin reuptake inhibitors, but clinical efficacy is equivocal. We aimed to reassess the efficacy of paroxetine dose escalation and quantify whether paroxetine dose escalation increases occupancy of the serotonin transporter (SERT) more than placebo dose escalation in a randomized controlled trial. We recruited 107 nonpsychotic, unipolar depressed outpatients ( $18-70$ years; Hamilton Depression Rating Scale $\left(H D R S_{17}\right)>$ I8) from primary care and psychiatric outpatient departments. After 6 weeks, open-label paroxetine $20 \mathrm{mg}$ per day (T0), nonresponding patients $\left(\mathrm{HDRS}_{17}\right.$ decrease $<50 \% ; n=60$ ) were randomized to double-blind paroxetine (30-50 mg per day as tolerable) or placebo dose escalation (paroxetine $20 \mathrm{mg}$ per day + placebo). Patients were followed until 6 weeks after randomization ( $\mathrm{TI}$ ). Forty-nine patients, drug free at study entry, underwent single-photon emission-computed tomography (SPECT) scanning before treatment and were scanned repeatedly at TO and TI. Paroxetine serum concentrations and SERT occupancy were determined at TO and TI $(n=32)$. We terminated the dose-escalation trial after an interim analysis. Thirty nonresponding patients were randomized to paroxetine (46.7 $\pm 5.5 \mathrm{mg}$ per day), 27 to placebo dose escalation. Response rates were 10/30 (33.3\%) and 10/27 (37.0\%), respectively. Repeated measurement analyses showed no significant effect for treatment $(p=0.88$, exceeding a priori stopping rules for futility $(p>0.5))$. Overall dropout was higher for placebo $(26.7 \%)$ than paroxetine $(3.3 \% ; p=0.03)$. Paroxetine dose escalation increased paroxetine serum concentrations $(p<0.00 \mathrm{I})$. SPECT measurements ( 12 patients randomized to paroxetine $(46.9 \pm 4.8 \mathrm{mg}$ ) and 14 to placebo dose escalation) showed no significant increase of midbrain SERT occupancy $(2.5 \pm 26.4 \%$, paroxetine; $3.1 \pm 25.8 \%$ placebo; $p=0.687)$ nor in diencephalon $(p=0.529)$. Paroxetine dose escalation in depressed patients has no clinical benefit over placebo dose escalation. This is explained by the absence of significant increases of SERT occupancy by paroxetine dose escalation, despite increased paroxetine serum concentrations (ISRCTN44| | |488).

Neuropsychopharmacology (2009) 34, 999- I010; doi:I 0.1038/npp.2008. I48; published online I October 2008
\end{abstract}

Keywords: paroxetine; drug dose-response relationship; major depressive disorder; serotonin transporter; SPECT; $\left[{ }^{123}\right.$ I] $\beta$-CIT

\section{INTRODUCTION}

Major depressive disorder (MDD) is often treated with antidepressants, particularly selective serotonin reuptake inhibitors (SSRIs). Unfortunately, response and remission

\footnotetext{
*Correspondence: Dr HG Ruhé, Department of Psychiatry, PAI- I75, Academic Medical Center, P.O. Box 22660, I I 00 DD Amsterdam, The Netherlands, Tel: + 3120 891 3501; Fax: + 3120 891 3701;

E-mail: H.G.Ruhe@AMC.UvA.NL

Received 29 April 2008; revised 13 August 2008; accepted I4 August 2008
}

rates are modest (30-50\%), which require additional strategies to gain remission (Kennedy et al, 2001; American Psychiatric Association, 2000). Switching (Rush et al, 2006) and augmentation (Trivedi et al, 2006a) have recently been evaluated. A third, and frequently applied option is dose escalation, recommended in treatment guidelines (Kennedy et al, 2001; American Psychiatric Association, 2000) and frequently used preceding other strategies. Only the recent NICE guideline is more reluctant in recommending dose escalation (NICE, 2004). Although an individual patient may improve after dose escalation, this could also represent a delayed drug response or reflect the natural course of the 
disease. Prolonged (up to 10 weeks), unaltered treatment with fluoxetine $20 \mathrm{mg}$ per day improved the response rates of initial week 6 nonresponders (Quitkin et al, 2003). Theoretically, the concept of dose escalation assumes linear dose-response relationships which have not been proven for SSRIs (Adli et al, 2005; Dunner and Dunbar, 1992). Therefore, the efficacy of dose escalation of SSRIs has been questioned (Ruhe et al, 2006; Adli et al, 2005; NICE, 2004; Baker et al, 2003).

Previous studies did not show improved clinical effectiveness of dose escalation, but had serious methodological weaknesses (Ruhe et al, 2006; Adli et al, 2005; Baker et al, 2003; Fava et al, 1994, 2002; Licht and Qvitzau, 2002; Schweizer et al, 1990, 2001; Benkert et al, 1997; Dornseif et al, 1989). All previous studies increased dosages probably too early (mostly after 3-4 weeks) and too abruptly, which may have obscured true dose-escalation effects by delayed effect of the standard doses and selective early dropout of patients receiving true dose escalation (Ruhe et al, 2006; Baker et al, 2003). Moreover, no study provided a rationale why dose escalation was ineffective.

The primary molecular target of SSRIs is the serotonin transporter (SERT). Imaging techniques such as positron emission tomography (PET) and single-photon emissioncomputed tomography (SPECT) allow in vivo labeling of SERT in the brain, which can be used to study their occupancy. Till date, several imaging studies measured SERT occupancy after short or prolonged treatment with SSRIs (Klein et al, 2006, 2007; Voineskos et al, 2007; Parsey et al, 2006; Takano et al, 2006; Catafau et al, 2006; Herold et al, 2006; Cavanagh et al, 2006; Erlandsson et al, 2005; Suhara et al, 2003; Kent et al, 2002; Meyer et al, 2001b, 2004; Hiltunen et al, 1998). Particularly, Meyer et al (2004) showed $60-80 \%$ SERT occupancy after standard clinical doses of SSRIs, and demonstrated curvilinear doseresponse relationships for SERT occupancy by SSRIs. However, high doses of SSRIs were rarely studied (Voineskos et al, 2007), and dose escalation was never studied.

Taking into account previous methodological criticisms and considering the molecular target of SSRIs, we have tested whether paroxetine dose escalation increases SERT occupancy and improves depressive symptoms more than placebo dose escalation. We performed a 6-week, multicenter, randomized study in depressed patients not responding to 6 weeks of paroxetine at $20 \mathrm{mg}$ per day. As a novel extension to previous clinical trials, and in order to elucidate the neurobiological basis for an expected lack of benefit of dose escalation, we included a SPECT-imaging approach. Herewith, we quantified whether paroxetine dose escalation increased SERT occupancy more than placebo dose escalation. This enabled us to relate clinical findings to the neurobiological correlate of SERT occupancy.

\section{MATERIALS AND METHODS}

\section{Participants}

Following approval by the institutional ethical committee and written informed consent, we recruited outpatients (1870 years) from primary care, our outpatient department, and public psychiatric settings between October 2003 and February 2007. Inclusion criteria were: MDD determined by the structured clinical interview for DSM-IV (First et al, 1999), and a Hamilton Depression Rating Scale (17 items; HDRS $_{17}$; Hamilton, 1960) score above 18. All participants were drug free or had undergone no more than one antidepressant treatment (other than paroxetine) at an effective dose for $\geqslant 6$ weeks for the present MDD-episode. By the latter criterion, we avoided treatment resistance as potential bias for inefficacy of dose escalation. Exclusion criteria, apart from pregnancy (or wish), were bipolar disorder, psychotic features, neurological cognitive impairments (ie dementia), primary anxiety and/or substance abuse disorders and acute, severe suicidal ideation. Contrary, we allowed secondary comorbid anxiety and/or substance abuse to increase applicability of our findings.

\section{Interventions}

Patients were treated by their referring physician or were referred to our outpatient department. After assessment at study entry, all patients were treated open label with paroxetine $20 \mathrm{mg}$ per day for 6 weeks (Figure 1), because paroxetine is the most prescribed SSRI in the Netherlands. When severe adverse effects occurred, dosages were reduced to $10 \mathrm{mg}$ per day and again increased to $20 \mathrm{mg}$ per day after 1 week. We randomized all patients who did not achieve $\geqslant 50 \%$ decrease in $\mathrm{HDRS}_{17}$ score after 6 weeks, relative to study entry. They received a true paroxetine or a placebo dose escalation added to paroxetine $20 \mathrm{mg}$ per day. Dose escalation was provided in blue capsules containing $10 \mathrm{mg}$ paroxetine or placebo. Randomization was stratified for treatment setting (SPECT group, outpatient department AMC, primary care, public psychiatry), gender, and age. Within strata, we applied a minimization method to achieve a balanced distribution. We concealed allocation by using an independently operated computer program.

Dose escalation consisted of incremental steps of one capsule every 5 days toward a maximum of $50 \mathrm{mg}$ per day $(20 \mathrm{mg}+3$ capsules). Patients were allowed to increase at a slower pace (eg by 7 days) or stop further escalation (eg $20 \mathrm{mg}+2$ capsules) according to adverse effects (Baker and Woods, 2003). No dosage adjustments were allowed during the last 3 weeks of the study. We checked adherence by pill counts and anamnesis (Saunders et al, 1998).

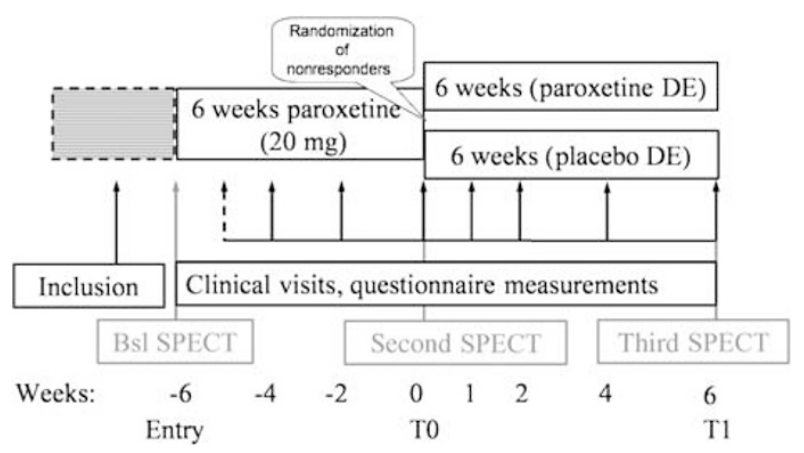

Figure I Design of the study; BsI SPECT, baseline scan; DE, dose escalation. 


\section{Outcomes and Measurements}

Primary clinical outcomes were $\mathrm{HDRS}_{17}$ scores, and the proportion of patients achieving response $(\geqslant 50 \%$ decrease in $\mathrm{HDRS}_{17}$ ) or remission $\left(\mathrm{HDRS}_{17} \leqslant 7\right)$. Secondary outcomes were total and specific (adverse effects/inefficacy) dropout rates, the Maier and Bech 6 item subscales of the $\mathrm{HDRS}_{17}$ (Ruhe et al, 2005; Faries et al, 2000), the Inventory for Depressive Symptomatology self-rated (IDS-SR 30 ; Rush et al, 1996) scores, the occurrence of adverse effects, and health-related quality of life (MOS-SF36; physical and mental component scales standardized to a general Dutch population; Aaronson et al, 1998).

We administered questionnaires at study entry, randomization (T0), and 6 weeks after randomization (T1). Depressive symptoms were also monitored at week 1,2 , and 4 using the Maier and Bech subscales and IDS-SR 30 (Figure 1). Three trained investigators administered clinician-rated questionnaires. Agreement between raters was good (intraclass correlation coefficient $=0.98$ ). Raters and patients were blinded for treatment.

\section{Subgroup for SPECT Imaging}

From all patients who entered the trial, we recruited patients who were drug free $(>4$ weeks and $\geqslant 5$ half-lives of a previous antidepressant) as potential candidates for SPECT imaging. These patients were asked to participate in the SPECT substudy if their age was between 25 and 55 years to reduce variability in SERT measurements by age (van Dyck et al, 2000). A total of 49 patients could thus be recruited for a first SPECT scan. None of these patients reported past or present use of 3,4-methylenedioxymethamphetamine. We made a second scan in those patients who completed 6 weeks of paroxetine treatment $(n=44$, including 12 responders), whereas only randomized nonresponders $(n=32)$ were invited for a third scan at the end of the study. We treated SPECT patients at the AMC outpatient department. Medication was supplied in pillboxes.

\section{SPECT Imaging and Analysis}

We performed SPECT imaging at study entry (baseline scan), T0 and T1 (Figure 1) between 14:00 and 22:00 hours, according to previously described procedures (de Win et al, 2005). We made all scans $230 \pm 18$ (SD) minutes after intravenous injection of approximately $100 \mathrm{MBq}$ iodine123-labeled $2 \beta$-carbomethoxy-3 $\beta$-(4-iodophenyl)-tropane $\left(\left[{ }^{123} \mathrm{I}\right] \beta\right.$-CIT), when the radioligand is at equilibrium for SERT binding in brain areas expressing high densities of SERTs (Pirker et al, 2000). To prevent thyroid uptake of ${ }^{123} \mathrm{I}$, all subjects received oral potassium-iodide solution. We performed SPECT imaging using a 12-detector singleslice brain-dedicated scanner (Neurofocus 810, Strichmann Medical Equipment; Cleveland, $\mathrm{OH}$ ) with a full-width at half-maximum resolution of $6.5 \mathrm{~mm}$, throughout the $20 \mathrm{~cm}$ field-of-view (http://www.neurophysics.com). Blood for paroxetine serum concentrations (PSC) was collected at T0 and T1 immediately before scanning. Serum was stored at $-20^{\circ} \mathrm{C}$ until analysis. PSC were determined in May 2007 using a validated HPLC-MS/MS method (therapeutic range
10-75 $\mu \mathrm{g} / \mathrm{l}$; Supplementary Appendix). The lower limit of quantification was $5 \mu \mathrm{g} / \mathrm{l}$, the lower limit of detection was $0.3 \mu \mathrm{g} / \mathrm{l}$.

After attenuation correction and reconstruction in $3 \mathrm{D}$ mode (http://www.neurophysics.com), we defined regions of interests (ROIs) for midbrain, diencephalon, and cerebellum by using validated templates (Supplementary Figure S1) (de Win et al, 2005). One examiner, blinded for scan session (baseline scan/T0/T1), positioned all ROIs in two series. Intraclass correlation coefficients were $>0.97$ for all ROIs. If the two series differed by $>5 \%$, scans were reevaluated by a second investigator. In the analyses we averaged the counts for the two series.

Using activity in cerebellum as indicator of nondisplaceable activity (nonspecific binding and free radioactivity) (Laruelle et al, 1988), we calculated specific to nonspecific binding ratios per scan as $\mathrm{BP}_{\mathrm{ND}}=\left(\right.$ Activity $_{\mathrm{ROI}}-$ Activity $\left._{\mathrm{CER}}\right) /$ Activity $_{\mathrm{CER}} \cdot \mathrm{BP}_{\mathrm{ND}}$ is proportional to transporter number under equilibrium conditions (Innis et al, 2007). In a different study, we found high reproducibility of SERT imaging with $\left[{ }^{123} \mathrm{I}\right] \beta$-CIT SPECT after repeated scanning of subjects, using the same camera and scanning protocol (de Win et al, submitted for publication). As primary outcomes, we calculated SERT occupancies at T0 or T1 relative to untreated baseline scan SERT availability: $\mathrm{OCC}_{\mathrm{T} 0 \text { or T1 }}=\left(\mathrm{BP}_{\mathrm{ND} \mathrm{Bsl}}-\mathrm{BP}_{\mathrm{ND} \mathrm{T} 0 \text { or T1 }}\right) / \mathrm{BP}_{\mathrm{ND} \mathrm{Bsl}}$.

\section{Power and Interim Analysis}

We performed a priori power calculations for two coprimary end points: (a) to detect a difference of $\geqslant 5$ points in $\mathrm{HDRS}_{17}$ scores between paroxetine and placebo dose escalation, although assuming a common standard deviation of 7 and using a one-tailed $\alpha=0.025$ and $\beta=0.05$, sample sizes of 60 per group were required; (b) for response rates (assumed to be $50 \%$ and $30 \%$ for paroxetine $v s$ placebo dose escalation) a two-tailed $\alpha=0.05$ and $\beta=0.20$ required 110 participants per group. Because previous dose escalation studies indicated no benefits relative to placebo dose escalation, we planned an interim analysis after SPECT data for had been collected on at least 30 randomized patients in the SPECT subgroup. Stopping criteria, using the most informative continuous scores in a mixed model, were predetermined using the O'Brien and Fleming (1979) approach, were undisclosed although performing the interim analysis, and were $p<0.0026$ in case of superiority and $p>0.50$ for futility (see Supplementary Appendix).

\section{Data Analyses}

Analyses were performed although blinded for treatment allocation. We based end point analyses on intention to treat (ITT), with last observation carried forward. To examine the effectiveness of paroxetine $v s$ placebo dose escalation, we compared the proportion of patients with response, remission, and dropouts at the end of study using $\chi^{2}$ or Fisher's exact test. We examined differences in mean continuous end points by ANCOVA with treatment as factor and value at randomization (T0) as covariate.

We used linear mixed models to assess differences in trends over time between groups in Maier, Bech, and IDS$\mathrm{SR}_{30}$ scores. Mean scores for these questionnaires were 
modeled as a function of the randomized group (paroxetine $v s$ placebo dose escalation), score at randomization, and time since randomization (categorical, four levels). The interaction between time $\times$ group was added to the model to test whether trends over time were different between the two treatment groups. We used the Akaike Information Criteria to choose the best fitting variance/covariance structure (unstructured, compound symmetry or first-order autoregressive) for each outcome parameter.

To examine changes in SERT occupancy between T0 and T1, we used ANCOVAs with treatment as factor, and SERT occupancy at T0 and age as covariates. In order to obtain maximum information of dose escalation in these analyses, we excluded patients that were likely nonadherent to paroxetine at T0 or T1 (PSC $<5 \mu \mathrm{g} / \mathrm{l}$ ). Thereafter, we plotted SERT occupancy against dose and PSC. We modeled dose-response in an $\mathrm{E}_{\max }$ model as OCC $=a \times \mathrm{PSC} /(b+\mathrm{PSC})$, in which $a$ represents maximal SERT occupancy and $b$ the PSC with 50\% SERT occupancy (Parsey et al, 2006; Takano et al, 2006; Catafau et al, 2006; Meyer et al, 2004; Suhara et al, 2003; Kent et al, 2002). We calculated $a$ and $b$ by fitting a nonlinear regression model that minimizes the sum of squares of the residuals. For quantification of differences in SERT occupancy between final responders and nonresponders, we used ANCOVA models corrected for differences at T0, age, and baseline scan SERT availability in diencephalon (Kugaya et al, 2004). We performed all analyses in SPSS v15.0.1.1 (www.spss.com).

\section{RESULTS}

\section{Patient Disposition}

A total of 107 patients (mean age $43.8 \pm 9.8$ ) started openlabel paroxetine (Figure 2). The response rate in the open phase was 27/107 (25.2\%), and 60 nonresponding patients were randomized for the double-blind phase. Randomization over the two treatment arms resulted in comparable groups (Table 1). A total of 51 patients completed the 6 week randomization phase including 31 from the SPECT study. We obtained at least 1 after randomization $\mathrm{HDRS}_{17}$ score for 57 patients.

HDRS $_{17}$ scores at study entry ( -6 weeks) were comparable in T0 responders $v s$ nonresponders (ANOVA, $\left.\mathrm{F}_{1,85}=1.972, p=0.164\right)$. At T0, HDRS 17 scores $( \pm \mathrm{SD})$ were $7.8 \pm 3.62(66.6 \pm 14.3 \%$ decrease $)$ in responders $v s$ $20.5 \pm 6.25(17.7 \pm 20.3 \%$ decrease $)$ in nonresponders.

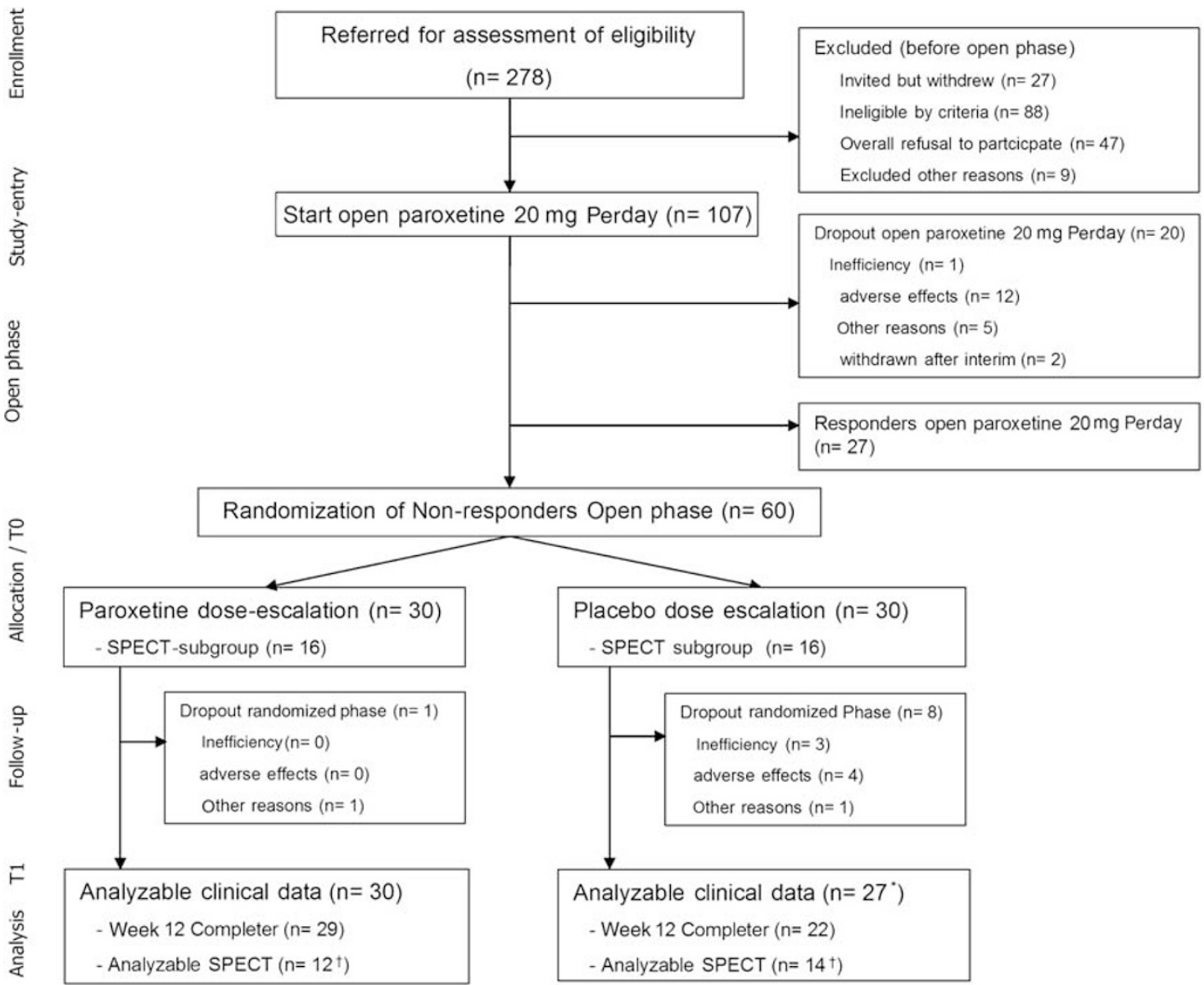

Figure 2 Recruitment and flow of participants. *Three patients who refused dose escalation after randomization, never ingested study drugs, and refused further questionnaires were excluded for end point analysis. ${ }^{\dagger}$ One single-photon emission-computed tomography (SPECT) patient dropped out early due to inefficacy, but for all SPECT patients' clinical data could be obtained. For SPECT analyses, six patients were excluded: one patient missed the TI scan (placebo dose escalation), three patients were likely nonadherent at T0 (paroxetine serum concentration $<5 \mu \mathrm{g} /$; ; all paroxetine dose escalation), and two were likely nonadherent at TI (one paroxetine dose escalation, one placebo dose escalation). 
Table I Characteristics of Nonresponding MDD Patients after 6 Weeks of Open Treatment With Paroxetine $20 \mathrm{mg}$ per day (Trial Population)

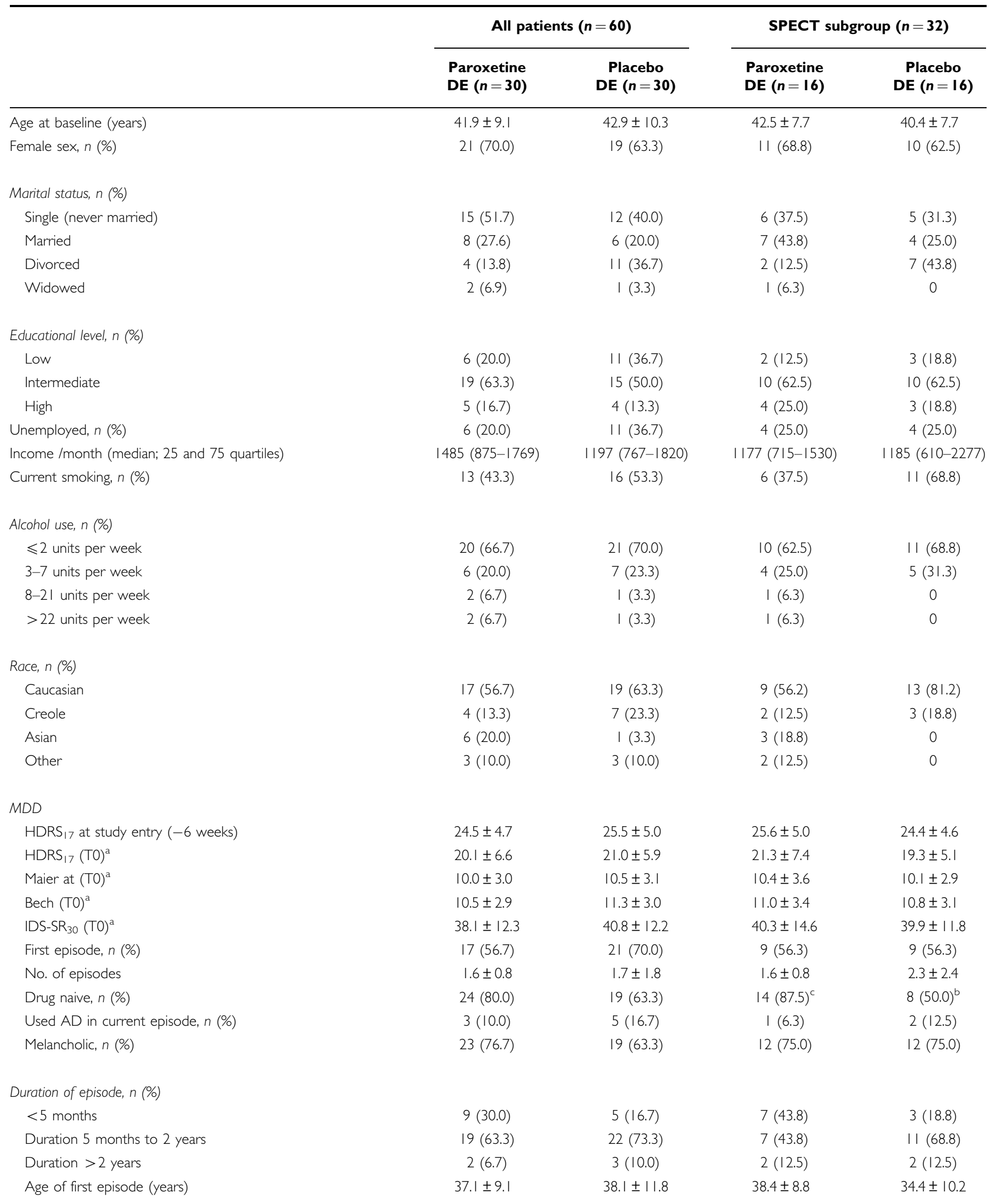




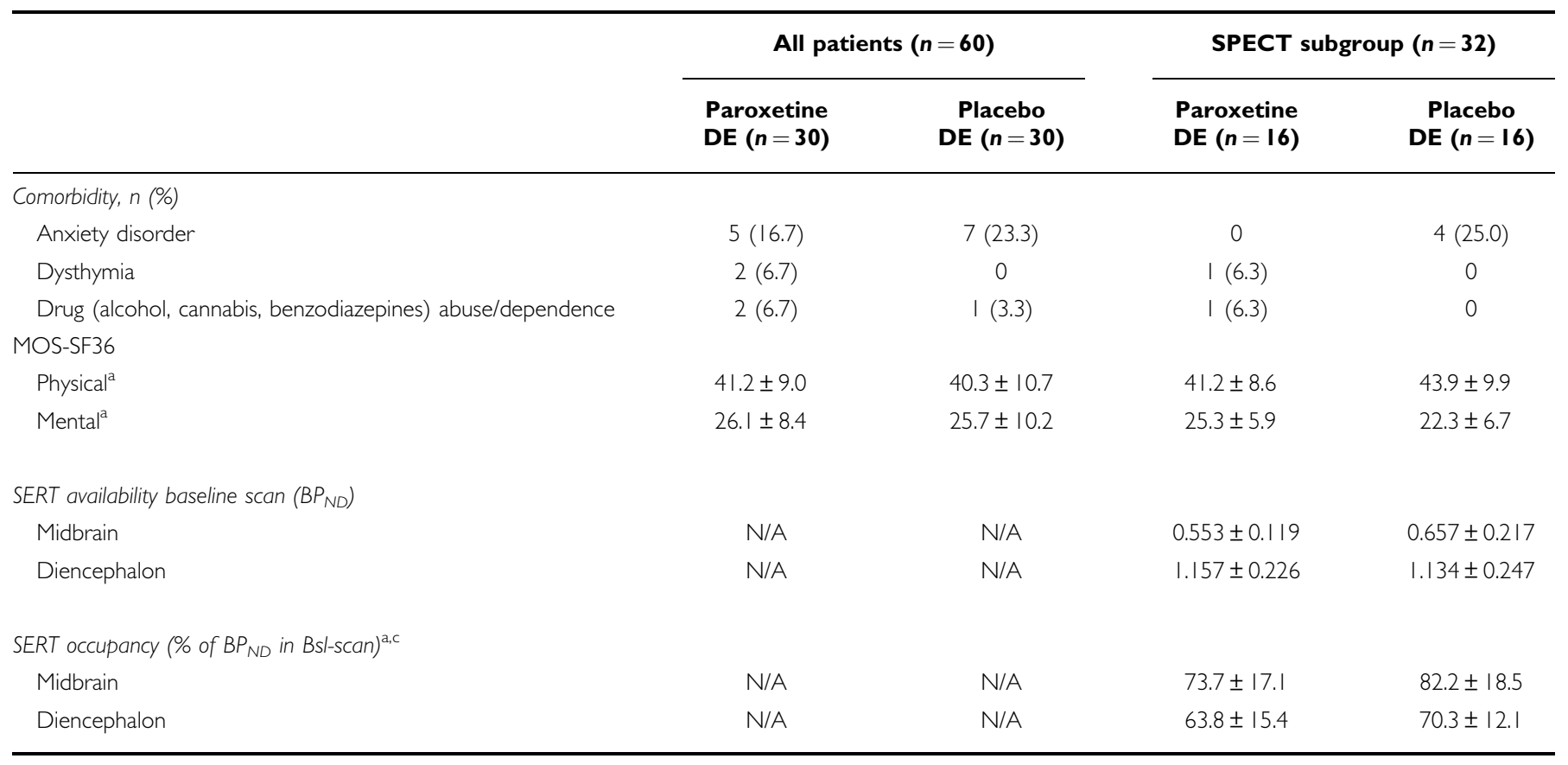

$\mathrm{BP}_{\mathrm{ND}}$, binding potential (non-displaceable); DE, dose escalation; MDD, major depressive disorder; PSC, paroxetine serum concentration.

Numbers represent means $( \pm S D)$ unless specified otherwise.

${ }^{a}$ At randomization (TO).

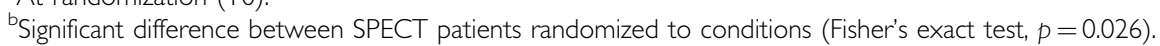

$c_{n}=29$, excluding three patients who were likely nonadherent at TO (PSC $\left.<5 \mu \mathrm{g} / \mathrm{l}\right)$.

\section{Clinical Effectiveness of Paroxetine vs Placebo Dose Escalation}

During dose escalation (T0-T1), 1, 8, and 21 patients reached final doses of 30,40 , and $50 \mathrm{mg}$ per day, respectively. The placebo group escalated to a comparable number of capsules $\left(\chi^{2}=0.895, \mathrm{df}=2, p=0.639\right)$. Adherence based on pill counts was comparable between both groups (Fisher's exact, $p=0.492$ ).

Paroxetine dose escalation did not yield better outcomes in depression severity and health-related quality of life compared with placebo dose escalation (ITT; Table 2). The robustness of this finding was confirmed in the longitudinal analysis (mixed model). Changes over time in the Maier subscale and IDS-SR 30 scores (Figure 3 ), and Bech subscale scores (available on request) were comparable between the two groups. Overall dropout was higher with placebo (26.7\%) than with paroxetine dose escalation (3.3\%; $p=0.03)$. Paroxetine dose escalation had significantly more adverse effects than placebo dose escalation, but this did not result in higher discontinuation rates due to adverse effects (Supplementary Table S1). Instead, adverse effects by paroxetine dose escalation moderately decreased over time, suggestive of habituation.

\section{SERT Occupancy and Clinical Response}

Out of 32 randomized patients in the SPECT subgroup, only 3 (9\%) previously used mirtazapine or fluoxetine in the current episode ( 1 patient stopped mirtazapine 4 weeks before scanning, others stopped $<2$ months before scanning). One patient missed the T1 scan. On the basis of PSC at randomization or $\mathrm{T} 1$, five patients in the SPECT subgroup (four with paroxetine and one with placebo dose escalation; Fisher's exact test, $p=0.172$; see Figure 2) with PSC $<5 \mu \mathrm{g} / \mathrm{l}$ were considered nonadherent, despite adherence according to pill counts. We excluded these five patients for analyses of changes in SERT occupancy after dose escalation, leaving $26 \mathrm{~T} 1$ scans analyzable for diencephalon occupancies after true or placebo dose escalation. Paroxetine dose escalation increased mean PSC from 36.2 to $154.3 \mu \mathrm{g} / \mathrm{l}$ (paired $t$-test, $p<0.001$ ), whereas mean PSC in placebo dose escalation remained unchanged (Supplementary Table S2). At randomization (T0), mean SERT occupancies $( \pm$ SEM) in the paroxetine dose escalation group were $76.2 \pm 4.70 \%$ in midbrain and $64.3 \pm 4.60 \%$ in diencephalon. For the placebo dose escalation group these were $84.6 \pm 4.95$ and $72.2 \pm 3.08 \%$, respectively. Neither paroxetine nor placebo dose escalation significantly increased SERT occupancy further (Figure 4a). Plotting PSC $v s$ SERT occupancy showed that PSCs $>50 \mu \mathrm{g} / \mathrm{l}$ were not associated with further increases of SERT occupancy in midbrain or diencephalon (Figure $4 \mathrm{~b}$ and c). Furthermore, individual changes in PSC (T0 to T1) were not significantly associated with changes in occupancy in midbrain $\left(\mathrm{F}_{1,24}=0.101, p=0.754\right)$ and diencephalon $\left(\mathrm{F}_{1,27}=1.332\right.$, $p=0.259$; Supplementary Figure S2).

We explored whether SERT occupancy was related to clinical response at $\mathrm{T} 1$ irrespective of paroxetine or placebo dose escalation. Responders at T1 $(n=12)$ had numerically higher SERT occupancy ( \pm SEM) in midbrain $(91.2 \pm 5.8 \%)$ and diencephalon $(69.2 \pm 2.8 \%)$ than nonresponders $(n=14 ; 77.8 \pm 5.1$ and $63.8 \pm 2.6 \%$, respectively; ANCOVA: $p=0.107$ and 0.178 ). These models used baseline scan 
Table 2 Depression and Health-Related Quality of Life Scores After 6 Weeks Paroxetine vs Placebo Dose Escalation (TI); all Patients and SPECT Subgroup

\begin{tabular}{|c|c|c|c|c|c|c|}
\hline & \multicolumn{2}{|c|}{ All patients $(n=57)$} & \multirow[b]{2}{*}{$p$} & \multicolumn{2}{|c|}{ SPECT subgroup $(n=32)$} & \multirow[b]{2}{*}{$p$} \\
\hline & $\begin{array}{l}\text { Paroxetine } \\
\text { DE }(n=30)\end{array}$ & $\begin{array}{c}\text { Placebo } \\
\text { DE }(n=27)\end{array}$ & & $\begin{array}{l}\text { Paroxetine } \\
\text { DE }(n=16)\end{array}$ & $\begin{array}{c}\text { Placebo } \\
\text { DE }(n=16)\end{array}$ & \\
\hline Mean dosage (mg per day) & $46.7 \pm 1.00$ & NA & - & $46.9 \pm 1.20$ & NA & - \\
\hline $\mathrm{HDRS}_{17}$ & $16.1 \pm 1.22$ & $15.3 \pm 1.28$ & 0.650 & $15.8 \pm 1.39$ & $14.5 \pm 1.39$ & 0.519 \\
\hline Maier subscale & $7.5 \pm 0.61$ & $7.5 \pm 0.64$ & 1.000 & $7.6 \pm 0.69$ & $7.4 \pm 0.69$ & 0.868 \\
\hline Response $^{\mathrm{a}}, \mathrm{n}(\%)$ & $10(33.3)$ & $10(37.0)$ & 0.788 & $4(25.0)$ & $8(50 \%)$ & 0.273 \\
\hline Remission $^{\mathrm{b}}, \mathrm{n}(\%)$ & $4(13.3)$ & $2(7.4)$ & 0.673 & I (6.3) & $2(12.5)$ & 1.000 \\
\hline IDS-SR ${ }_{30}{ }^{c}$ & $34.8 \pm 1.83$ & $32.5 \pm 2.05$ & 0.406 & $39.2 \pm 2.38$ & $32.0 \pm 2.38$ & 0.042 \\
\hline \multicolumn{7}{|l|}{ MOS-SF36 $6^{\mathrm{d}}$} \\
\hline Physical & $41.8 \pm 0.93$ & $42.4 \pm 1.06$ & 0.679 & $42.5 \pm 1.33$ & $44.1 \pm 1.33$ & 0.399 \\
\hline
\end{tabular}

DE, dose escalation.

Scores at end point of the study are based on intention to treat, with last observation carried forward for early dropouts. Values are means \pm SD, corrected for (mean) scores at randomization (TO) (ANCOVA).

${ }^{\mathrm{a}} \geqslant 50 \%$ decrease in $\mathrm{HDRS}_{17}$ with baseline score ( -6 weeks) as reference; Fisher's exact test.

${ }^{\mathrm{b}} \mathrm{HDRS}_{17} \leqslant 7$; Fisher's exact test.

${ }^{c}$ Owing to missing values: $n=29$, paroxetine $D E$ and $n=23$, placebo DE for all patients.

${ }^{d}$ Owing to missing values: $n=29$, paroxetine $D E$ and $n=22$, placebo DE for all patients.
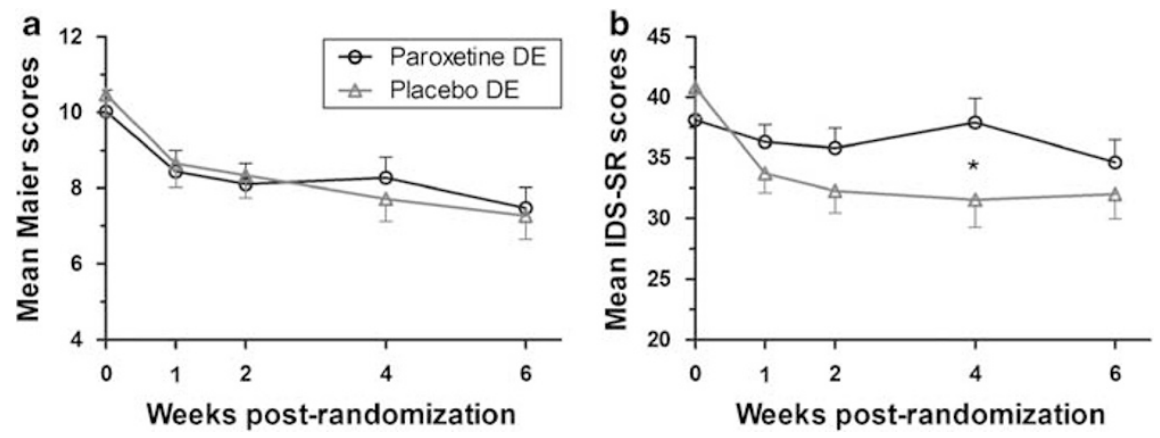

Figure 3 (a,b) Changes over time in Maier and inventory for depressive symptomatology self-rated (IDS-SR) scores after randomization. Points represent mean Maier (a) and IDS-SR (b) scores ( \pm SEM) adjusted for scores at randomization (T0) for paroxetine $(n=30)$ and placebo $(n=27)$ dose escalation.

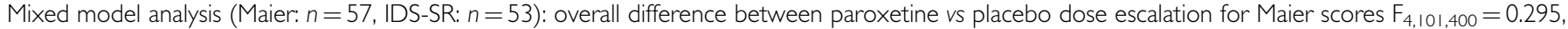
$p=0.880$, and for IDS-SR $F_{4,45,519}=1.516, p=0.213$. *Mean IDS-SR score at week 4 differed significantly in favor of placebo dose escalation $\left(t_{49,161}=2.1 \mathrm{I}\right.$, $p=0.040) ; \mathrm{DE}$, dose escalation.

diencephalon SERT availability as covariate as this accounted for a major part of variance $\left(\mathrm{F}_{1,21}=4.831\right.$, $p=0.039$ and $\mathrm{F}_{1,22}=10.407, p=0.004$, respectively). Contrary, T1 SERT occupancy in midbrain or diencephalon did not significantly predict the percentage decrease in $\mathrm{HDRS}_{17}$ in linear regression, or response status in logistic regression (neither when corrected for baseline scan SERT availability in diencephalon or age).

\section{DISCUSSION}

In this randomized trial, we examined clinical effectiveness of dose escalation in MDD patients, who were nonresponders to 6 weeks of $20 \mathrm{mg}$ per day paroxetine, and explored potential underlying mechanisms. Despite markedly in- creased drug exposure, paroxetine dose escalation to $30-$ $50 \mathrm{mg}$ per day did not improve depressive symptoms more than placebo dose escalation, but was associated with more adverse effects. Concomitantly, increased PSCs were not associated with substantially greater SERT occupancy, indicating that standard paroxetine doses ( $20 \mathrm{mg}$ per day) already resulted in maximum SERT occupancy.

\section{Clinical Outcomes of Dose Escalation in Nonresponders}

The dose-response relationship for paroxetine was previously examined in fixed dose, parallel group designs. A total of $20 \mathrm{mg}$ per day and higher paroxetine doses yielded similar clinical improvements (Dunner and Dunbar, 1992). Similar findings were reported from parallel group, fixed dose studies of other SSRIs (Adli et al, 2005). Accordingly, 
a

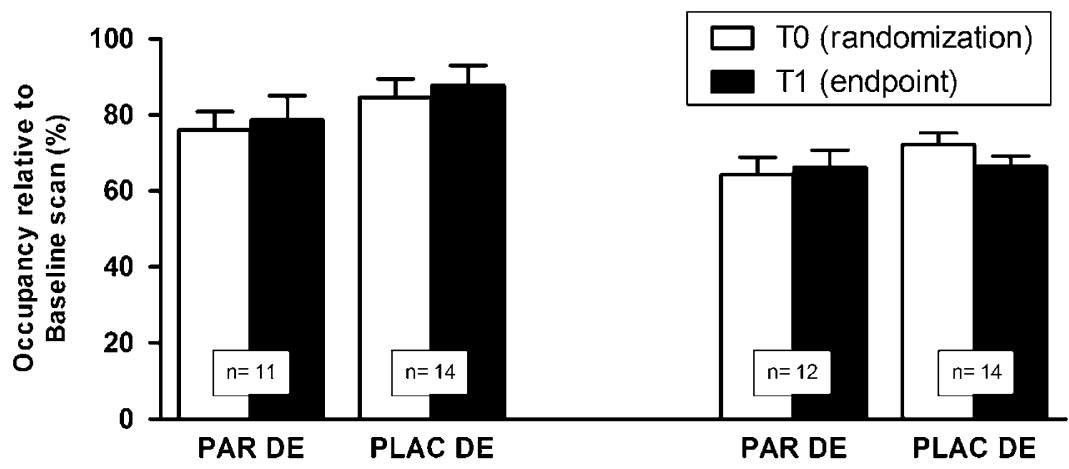

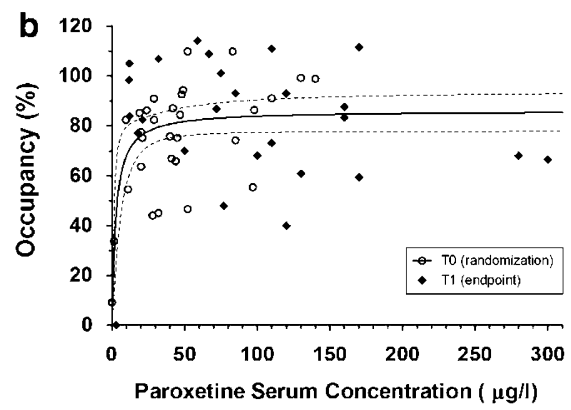

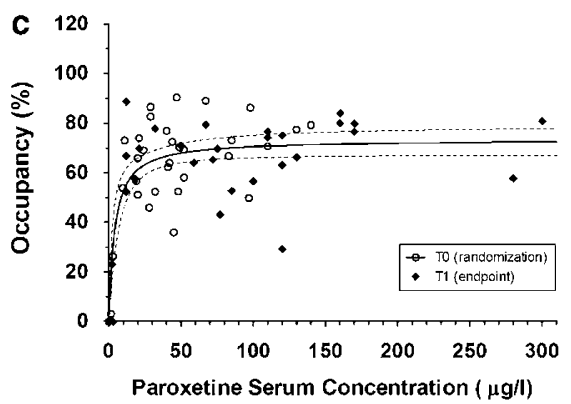

Figure $4(\mathrm{a}-\mathrm{c})$ Serotonin transporter (SERT) occupancy during randomized dose escalation of paroxetine. Changes over time and relation with paroxetine serum concentration. (a) Mean SERT occupancy ( \pm SEM) for paroxetine dose escalation and placebo dose escalation at randomization (T0) and

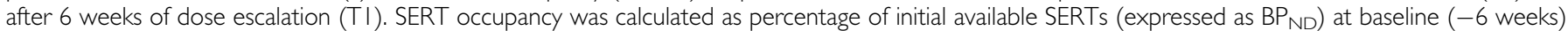
scans (see text). Changes in SERT occupancy between TO and TI for paroxetine dose escalation and placebo dose escalation were nonsignificant in ANCOVA models correcting for age and differences in TO SERT occupancy (midbrain: $F_{1,21}=0.167, p=0.687$; diencephalon: $F_{1,22}=0.409, p=0.529$ ). For one patient, insufficient midbrain was scanned at study entry to compute subsequent SERT occupancies. (b, $c)$ Data for randomized patients used from both T0 (open circles) and TI (diamonds). Dose - occupancy relationships are modeled as OCC $=a \times(\mathrm{PSC} /(b+\mathrm{PSC}))$. For midbrain (b): $a=86.0 \pm 4.03$ (SE), $b=2.65 \pm 1.39$ ( $n=30$ at T0 and $n=27$ at TI); for Diencephalon (c) $a=73.3 \pm 2.28, b=3.97 \pm 1.07$ ( $n=32$ at T0 and $n=29$ at TI). Dashed lines represent 95\% confidence interval of fitting; DE, dose escalation; OCC, occupancy; PAR, paroxetine; PLAC, placebo; PSC, paroxetine serum concentration.

the usefulness of dose escalation in nonresponders to paroxetine and other SSRIs has been questioned (Ruhe et al, 2006; Adli et al, 2005; Baker et al, 2003). However, the underlying studies had methodological short comings, and dose escalation remains a recommended standard approach for nonresponders (Kennedy et al, 2001; American Psychiatric Association, 2000).

If dose escalation is applied too early (before week 6), randomization of 'late responders' will likely dilute the difference between true and placebo dose escalation, resulting in potentially false negative findings. Although one study reported randomized dose escalation of sertraline after 6 weeks of treatment, this was compromised by a nonrandomized dose increase 2 weeks before randomization (Licht and Qvitzau, 2002).

The benefits of dose escalation might be underestimated if actively treated patients dropout early due to adverse effects (Baker and Woods, 2003) or become more nonadherent. Our schedule for dose escalation did not increase dropout. Hypothetically, patients receiving a paroxetine dose escalation might have interpreted the increased level of adverse effects as subjective clue of greater drug effects, encouraging them to persevere in the trial. At first sight, a misbalance in adherence is suggested with four patients with paroxetine $v s$ one patient with placebo dose escalation having low PSCs. However, this was not due to dose escalation. As mentioned in Figure 2, in three patients, low PSCs at T0 already classified them as likely nonadherent, with only one paroxetine $v s$ one placebo dose escalation patient becoming likely nonadherent during dose escalation (T0-T1). Therefore, we think that neither adverse effects nor nonadherence account for the observed inefficacy of dose escalation.

Thus, the present study overcomes methodological limitations of previous SSRI dose escalation studies by using a randomized, placebo controlled, double-blind dose escalation in nonresponders to 6 weeks treatment with a standard dose of paroxetine. We also avoided treatment resistance as a factor for inefficacy of dose escalation by inclusion of patients who received no more than one effective antidepressant trial for the current episode. Under these conditions paroxetine was not superior to placebo in dose escalation. Moreover, our study was more inclusive than most previous ones and thus may be more applicable to 'real-world' first-line antidepressant treatment. This may also explain why we observed lower response and remission rates than previous studies.

\section{Neurobiological Effects of Dose Escalation}

Our pharmacokinetic and imaging measurements were designed to explore why paroxetine dose escalation would 
or would not improve treatment outcomes. Our imaging of SERT occupancy bypasses potential bias by inclusion of patients with ultrarapid drug metabolism, which is often causally linked to nonresponse. Hypothetically, the clinical selection of nonresponders eligible for dose escalation might represent a selection of patients not reaching high levels of SERT occupancy.

Comparing SERT occupancies of different SSRI doses faces several methodological challenges. First, the assessment of occupancy requires knowledge on the available number of SERTs. Owing to interindividual differences in available SERTs, only assessments with individual drug-free baseline scans yield reliable data. Second, a given drug dose may yield a range of serum concentrations due to interpatient pharmacokinetic differences. Hence, associations based on serum concentrations are more reliable than those based on administered dose. Finally, intraindividual comparisons of occupancy changes following dose escalation are more powerful than those with historic data.

Against this background, Voineskos et al (2007) recently reported high SERT occupancies in striatum $(\sim 85 \%)$, thalamus $(\sim 79 \%)$, and midbrain $(\sim 98 \%)$ in 12 depressed patients exposed to $>4$ weeks of venlafaxine $225-450 \mathrm{mg}$ per day, sertraline $150-200 \mathrm{mg}$ per day, or citalopram 60$80 \mathrm{mg}$ per day in a $\left[{ }^{11} \mathrm{C}\right] \mathrm{DASB}$ PET study. They concluded that high doses significantly increased occupancy compared with an average of $80 \%$ SERT occupancy determined in previous studies with standard SSRI doses (Meyer, 2007; Meyer et al, 2004), which would favor the concept of dose escalation. However, they did not determine occupancy relative to baseline scans of the same patients without medication, nor at standard doses. We performed drug-free study-entry scans, in addition, $>90 \%$ of patients did not use antidepressants for the current episode of MDD. Furthermore, low therapeutic dosages of several SSRIs also yielded high SERT occupancy in most studies (Klein et al, 2006, 2007; Parsey et al, 2006; Takano et al, 2006; Catafau et al, 2006; Herold et al, 2006; Erlandsson et al, 2005; Suhara et al, 2003; Kugaya et al, 2003; Kent et al, 2002; Meyer et al, 2001b; Hiltunen et al, 1998). The present study resolves this controversy by showing that fourfold increases of PSC on paroxetine dose escalation did not significantly increase SERT occupancy. This offers an explanation for our findings: SERT occupancy is limited by a ceiling effect. A PSC achieved with a $20 \mathrm{mg}$ per day paroxetine dose is sufficient to yield maximum SERT occupancy (Figure $4 \mathrm{~b}$ and c). If low doses already yield maximum SERT occupancy, dose escalation cannot be expected to increase treatment efficacy, which is in line with our clinical findings. Our results do not necessarily challenge the relationships between dose, SERT occupancy, and clinical response but rather suggest that these relationships exist mainly at low and subtherapeutic doses. Furthermore, the relationship between SERT occupancy and response might be confounded by other factors such as SERT gene polymorphisms.

In a recent study, Owens et al (2008) showed increased SERT occupancy with increasing paroxetine CR doses (12.5-75 mg per day) in an ex vivo model using human transporter transfected cells, which might be at odds with our findings. However, validation of this ex vivo method (in cultured cells) with concomitant in vivo SPECT or PET SERT occupancy (the gold standard) is not yet available. In addition, Zitterl et al (2008) found a significant relation between SERT occupancy and clinical response in obsessivecompulsive disorder treated with clomipramine (150 mg per day), but did not study the effects of dose escalation in their study. Therefore, our study optimally quantifies the neurobiological effects of dose escalation of antidepressants in patients.

\section{Critique of Methods}

For logistic reasons, we used $\left[{ }^{123} \mathrm{I}\right] \beta$-CIT for SPECT imaging, which is a nonselective radioligand, and also binds to dopamine transporters (DAT; eg substantia nigra) and norepinephrine transporter (NET; eg locus coeruleus) (Neumeyer et al, 1991, 1996; Innis et al, 1991). Furthermore, imaging studies indicated increased striatal DAT binding after treatment with paroxetine (Booij et al, 2007; Kugaya et al, 2003), especially when the occipital cortex was used as a reference (Booij et al, 2007). Nevertheless, uptake in midbrain and diencephalon is considered to reflect predominantly SERT (Laruelle et al, 1993), as these structures are rich of SERT relative to DAT and NET. Therefore, although this nonselectivity might have concealed changes in SERT occupancies due to additional DAT or NET binding, we think our findings in diencephalon and midbrain mainly reflect SERT occupancy. Nevertheless, it would be challenging to replicate our study using a selective ligand for SERT like $\left[{ }^{11} \mathrm{C}\right] \mathrm{DASB}$ for PET or $\left[{ }^{123} \mathrm{I}\right] \mathrm{ADAM}$ for SPECT imaging. By the start of our study, $\left[{ }^{123} \mathrm{I}\right] \mathrm{ADAM}$ was not routinely available in the Netherlands.

Our study did not investigate secondary effects of paroxetine. Many adaptive pre- and postsynaptic effects of chronic administration of SSRIs have been documented, including neuroadaptive alterations in serotonin receptors and intracellular signaling pathways (Blendy, 2006; Kim et al, 2002; Meyer et al, 2001a; Davidson and Stamford, 2000; Benmansour et al, 1999; Blier and De Montigny, 1994), as well as time-dependent effects on neurogenesis (Martinowich and Lu, 2008; Djavadian, 2004; Malberg et al, 2000). These hypothetical additional effects of dose escalation remain to be investigated. Nevertheless, neither the results of our trial nor the findings from previous randomized controlled trials indicate that dose escalation is an efficacious strategy for SSRI nonresponders in MDD (Ruhe et al, 2006; Adli et al, 2005; Baker et al, 2003).

The fourfold increase of PSC after dose escalation from 20 to $50 \mathrm{mg}$ per day may question adherence of patients in the open phase of the study. However, paroxetine inhibits the cytochrome $\mathrm{P}_{450}$ enzyme 2D6, also responsible for the metabolism of paroxetine. Therefore, nonlinear increases of PSC reflect normal paroxetine pharmacokinetics (Anonymous, 2008).

Our study was discontinued after an interim analysis with relatively small patient numbers. However, the criteria for premature trial termination regarding futility had been prespecified, making it highly unlikely that we overlooked clinically relevant differences. Moreover, the neurobiological parts of our study provide a rationale why even with much larger patient numbers no substantially different outcome can be expected. On the other hand, premature stopping reduced the power to examine whether subgroups of patients were more responsive to dose escalation. 
This study was not designed to test the efficacy of paroxetine per se, as this is well established in patients with severe MDD ( $\left.\mathrm{HDRS}_{17}>18\right)$ (NICE, 2004; Kennedy et al, 2001; American Psychiatric Association, 2000). Therefore, we did not include a pure placebo arm. Rather we investigated dose escalation, and accordingly only included placebo during dose escalation. This approach is similar to eg the $\mathrm{STAR}^{*} \mathrm{D}$ project, which interestingly reported similar response rates for open treatment with citalopram (Trivedi et al, 2006b).

\section{CONCLUSION}

Previous studies had failed to demonstrate a clinical benefit of dose escalation by SSRIs, but had methodological limitations (Ruhe et al, 2006; Adli et al, 2005; Baker et al, 2003). Addressing those limitations, our trial replicates that dose escalation of paroxetine above the $20 \mathrm{mg}$ per day standard dose has no additional clinical benefit. As a novel extension, we revealed the underlying neurobiological mechanism for this inefficacy: maximum SERT occupancy was already reached with the standard dose. Similarly, high SERT occupancies reported with low doses of other SSRIs suggest that our conclusion may be applicable to the entire drug class. However, this does not exclude that dose escalation has clinical benefits for antidepressants with additional molecular targets, eg the norepinephrine transporter, such as venlafaxine. This drug has shown dose dependency of the clinical response in fixed dose studies (Thase et al, 2006; Rudolph et al, 1998).

If dose escalation is not promising for paroxetine and presumably other SSRIs, two clinical options remain for the treatment of nonresponders to standard doses. These are either continuation of treatment until 10 weeks while waiting for a potential delayed response, or a change to a different and potentially more effective treatment strategy. Both strategies will further improve response rates, but studies directly comparing these strategies have not yet been performed.

\section{ACKNOWLEDGEMENTS}

We thank the patients in this study for their participation, and especially thank the patients that were willing to participate in the SPECT study. We also thank all participating general practitioners in the area of Amsterdam Oost and Zuidoost, Hoofddorp, Nieuw Vennep, and Abcoude for their inclusions and referrals for the study. Mrs E Miedema MD and Mrs MC ten Doesschate MD were indispensable for their help in rating questionnaires. Mrs M Haages managed randomization and maintained blinding. This study was financed by a grant from the Netherlands Organisation for Health Research and Development (ZonMw), program Mental Health, education of investigators in mental health to HG Ruhé (OOG; 100-002-002). We especially thank Professor ME Thase MD for his constructive comments on a previous version of the paper.

\section{DISCLOSURE/CONFLICTS OF INTEREST}

All authors declared no conflict of interests.

\section{REFERENCES}

Aaronson NK, Muller M, Cohen PD, Essink-Bot ML, Fekkes M, Sanderman R et al (1998). Translation, validation, and norming of the Dutch language version of the SF-36 Health Survey in community and chronic disease populations. J Clin Epidemiol 51: 1055-1068.

Adli M, Baethge C, Heinz A, Langlitz N, Bauer M (2005). Is dose escalation of antidepressants a rational strategy after a mediumdose treatment has failed? A systematic review. Eur Arch Psychiatry Clin Neurosci 255: 387-400.

American Psychiatric Association (2000). Practice guideline for the treatment of patients with major depressive disorder (revision). American Psychiatric Association. Am J Psychiatry 157: 1-45.

Anonymous (2008). Paxil ${ }^{\mathbb{R}}$ Prescribing Information and Medication Guide PXL:47PI (available at http://us.gsk.com/products/ assets/us_paxil.pdf) In: GlaxoSmithKline: Research Triangle Park, North Carolina. pp 1-44.

Baker CB, Tweedie R, Duval S, Woods SW (2003). Evidence that the SSRI dose response in treating major depression should be reassessed: a meta-analysis. Depress Anxiety 17: 1-9.

Baker CB, Woods SW (2003). Is there a SSRI dose response in treating major depression? The case for re-analysis of current data and for enhancing future study design. Depress Anxiety 17: $10-18$.

Benkert O, Szegedi A, Wetzel H, Staab HJ, Meister W, Philipp M (1997). Dose escalation $v s$ continued doses of paroxetine and maprotiline: a prospective study in depressed out-patients with inadequate treatment response. Acta Psychiatr Scand 95: 288-296.

Benmansour S, Cecchi M, Morilak DA, Gerhardt GA, Javors MA, Gould GG et al (1999). Effects of chronic antidepressant treatments on serotonin transporter function, density, and mRNA level. J Neurosci 19: 10494-10501.

Blendy JA (2006). The role of CREB in depression and antidepressant treatment. Biol Psychiatry 59: 1144-1150.

Blier P, De Montigny C (1994). Current advances and trends in the treatment of depression. Trends Pharmacol Sci 15: 220-226.

Booij J, de Jong J, de Bruin K, Knol R, de Win MM, van Eck-Smit BL (2007). Quantification of striatal dopamine transporters with $\left[{ }^{123} \mathrm{I}\right]$-FP-CIT SPECT is influenced by the selective serotonin reuptake inhibitor paroxetine: a double-blind, placebo-controlled, crossover study in healthy control subjects. J Nucl Med 48: $359-366$.

Catafau AM, Perez V, Plaza P, Pascual JC, Bullich S, Suarez M et al (2006). Serotonin transporter occupancy induced by paroxetine in patients with major depression disorder: a $\left[{ }^{123} \mathrm{I}\right]-\mathrm{ADAM}$ SPECT study. Psychopharmacology (Berl) 189: 145-153.

Cavanagh J, Patterson J, Pimlott S, Dewar D, Eersels J, Dempsey MF et al (2006). Serotonin transporter residual availability during long-term antidepressant therapy does not differentiate responder and nonresponder unipolar patients. Biol Psychiatry 59: 301-308.

Davidson C, Stamford JA (2000). Effect of chronic paroxetine treatment on $5-\mathrm{HT}_{1 \mathrm{~B}}$ and $5-\mathrm{HT}_{1 \mathrm{D}}$ autoreceptors in rat dorsal raphe nucleus. Neurochem Int 36: 91-96.

de Win MM, Habraken JB, Reneman L, van den Brink W, den Heeten GJ, Booij J (2005). Validation of $\left[{ }^{123} \mathrm{I}\right] \beta$-CIT SPECT to assess serotonin transporters in vivo in humans: a double-blind, placebo-controlled, crossover study with the selective serotonin reuptake inhibitor citalopram. Neuropsychopharmacology 30: 996-1005.

Djavadian RL (2004). Serotonin and neurogenesis in the hippocampal dentate gyrus of adult mammals. Acta Neurobiol Exp (Wars) 64: 189-200.

Dornseif BE, Dunlop SR, Potvin JH, Wernicke JF (1989). Effect of dose escalation after low-dose fluoxetine therapy. Psychopharmacol Bull 25: 71-79. 
Dunner DL, Dunbar GC (1992). Optimal dose regimen for paroxetine. J Clin Psychiatry 53(Suppl): 21-26.

Erlandsson K, Sivananthan T, Lui D, Spezzi A, Townsend CE, Mu S et al (2005). Measuring SSRI occupancy of SERT using the novel tracer $\left[{ }^{123}\right.$ I]ADAM: a SPECT validation study. Eur J Nucl Med Mol Imaging 32: 1329-1336.

Faries D, Herrera J, Rayamajhi J, DeBrota D, Demitrack M, Potter WZ (2000). The responsiveness of the Hamilton Depression Rating Scale. J Psychiatr Res 34: 3-10.

Fava M, Alpert J, Nierenberg A, Lagomasino I, Sonawalla S, Tedlow $J$ et al (2002). Double-blind study of high-dose fluoxetine vs lithium or desipramine augmentation of fluoxetine in partial responders and nonresponders to fluoxetine. J Clin Psychopharmacol 22: 379-387.

Fava M, Rosenbaum JF, McGrath PJ, Stewart JW, Amsterdam JD, Quitkin FM et al (1994). Lithium and tricyclic augmentation of fluoxetine treatment for resistant major depression: a double-blind, controlled study. Am J Psychiatry 151: 1372-1374.

First MB, Spitzer RL, Gibbon M, Williams JBW (1999). Structured Clinical Interview for DSM-IV Axis I Disorders Patient Edition (SCID-I/P version 2.0). Translated in Dutch by Groenestijn MAC, Akkerhuis GW, Kupka RW, Schneider N, Nolen WA (eds). Swets \& Zeitlinger B.V.: Lisse, The Netherlands.

Hamilton M (1960). A rating scale for depression. J Neurol Neurosurg Psychiatry 23: 56-61.

Herold N, Uebelhack K, Franke L, Amthauer H, Luedemann L, Bruhn $\mathrm{H}$ et al (2006). Imaging of serotonin transporters and its blockade by citalopram in patients with major depression using a novel SPECT ligand $\left[{ }^{123} \mathrm{I}\right]-A D A M$. J Neural Transm 113: $659-670$

Hiltunen J, Akerman KK, Kuikka JT, Bergstrom KA, Halldin C, Nikula $\mathrm{T}$ et al (1998). Iodine-123 labeled nor-beta-CIT as a potential tracer for serotonin transporter imaging in the human brain with single-photon emission tomography. Eur J Nucl Med 25: $19-23$.

Innis R, Baldwin R, Sybirska E, Zea Y, Laruelle M, al Tikriti M et al (1991). Single photon emission computed tomography imaging of monoamine reuptake sites in primate brain with $\left[{ }^{123} \mathrm{I}\right] \mathrm{CIT}$. Eur J Pharmacol 200: 369-370.

Innis RB, Cunningham VJ, Delforge J, Fujita M, Gjedde A, Gunn $\mathrm{RN}$ et al (2007). Consensus nomenclature for in vivo imaging of reversibly binding radioligands. J Cereb Blood Flow Metab 27: 1533-1539.

Kennedy SH, Lam RW, Cohen NL, Ravindran AV (2001). Clinical guidelines for the treatment of depressive disorders. IV. Medications and other biological treatments. Can J Psychiatry 46(Suppl 1): 38S-58S.

Kent JM, Coplan JD, Lombardo I, Hwang DR, Huang Y, Mawlawi O et al (2002). Occupancy of brain serotonin transporters during treatment with paroxetine in patients with social phobia: a positron emission tomography study with $\left[{ }^{11} \mathrm{C}\right] \mathrm{McN} 5652$. Psychopharmacology (Berl) 164: 341-348.

Kim SW, Park SY, Hwang O (2002). Up-regulation of tryptophan hydroxylase expression and serotonin synthesis by sertraline. Mol Pharmacol 61: 778-785.

Klein N, Sacher J, Geiss-Granadia T, Attarbaschi T, Mossaheb N, Lanzenberger $\mathrm{R}$ et al (2006). In vivo imaging of serotonin transporter occupancy by means of SPECT and $\left[{ }^{123} \mathrm{I}\right] \mathrm{ADAM}$ in healthy subjects administered different doses of escitalopram or citalopram. Psychopharmacology (Berl) 188: 263-272.

Klein N, Sacher J, Geiss-Granadia T, Mossaheb N, Attarbaschi T, Lanzenberger $\mathrm{R}$ et al (2007). Higher serotonin transporter occupancy after multiple dose administration of escitalopram compared to citalopram: an $\left[{ }^{123} \mathrm{I}\right] \mathrm{ADAM}$ SPECT study. Psychopharmacology (Berl) 191: 333-339.

Kugaya A, Sanacora G, Staley JK, Malison RT, Bozkurt A, Khan S et al (2004). Brain serotonin transporter availability predicts treatment response to selective serotonin reuptake inhibitors. Biol Psychiatry 56: 497-502.

Kugaya A, Seneca NM, Snyder PJ, Williams SA, Malison RT, Baldwin RM et al (2003). Changes in human in vivo serotonin and dopamine transporter availabilities during chronic antidepressant administration. Neuropsychopharmacology 28: 413-420.

Laruelle M, Baldwin RM, Malison RT, Zea-Ponce Y, Zoghbi SS, al Tikriti MS et al (1993). SPECT imaging of dopamine and serotonin transporters with $\left[{ }^{123} \mathrm{I}\right] \beta$-CIT: pharmacological characterization of brain uptake in nonhuman primates. Synapse 13: 295-309.

Laruelle M, Vanisberg MA, Maloteaux JM (1988). Regional and subcellular localization in human brain of $\left[{ }^{3} \mathrm{H}\right]$ paroxetine binding, a marker of serotonin uptake sites. Biol Psychiatry 24: 299-309.

Licht RW, Qvitzau S (2002). Treatment strategies in patients with major depression not responding to first-line sertraline treatment: a randomised study of extended duration of treatment, dose increase or mianserin augmentation. Psychopharmacology (Berl) 161: 143-151.

Malberg JE, Eisch AJ, Nestler EJ, Duman RS (2000). Chronic antidepressant treatment increases neurogenesis in adult rat hippocampus. J Neurosci 20: 9104-9110.

Martinowich K, Lu B (2008). Interaction between BDNF and serotonin: role in mood disorders. Neuropsychopharmacology 33: $73-83$.

Meyer JH (2007). Imaging the serotonin transporter during major depressive disorder and antidepressant treatment. J Psychiatry Neurosci 32: 86-102.

Meyer JH, Kapur S, Eisfeld B, Brown GM, Houle S, DaSilva J et al (2001a). The effect of paroxetine on $5-\mathrm{HT}(2 \mathrm{~A})$ receptors in depression: an $\left[{ }^{18} \mathrm{~F}\right]$ setoperone PET imaging study. $\mathrm{Am} \mathrm{J}$ Psychiatry 158: 78-85.

Meyer JH, Wilson AA, Ginovart N, Goulding V, Hussey D, Hood K et al (2001b). Occupancy of serotonin transporters by paroxetine and citalopram during treatment of depression: a $\left[{ }^{11} \mathrm{C}\right] \mathrm{DASB}$ PET imaging study. Am J Psychiatry 158: 1843-1849.

Meyer JH, Wilson AA, Sagrati S, Hussey D, Carella A, Potter WZ et al (2004). Serotonin transporter occupancy of five selective serotonin reuptake inhibitors at different doses: an $\left[{ }^{11} \mathrm{C}\right] \mathrm{DASB}$ positron emission tomography study. Am J Psychiatry 161: 826-835.

Neumeyer JL, Tamagnan G, Wang S, Gao Y, Milius RA, Kula NS et al (1996). N-substituted analogs of 2 beta-carbomethoxy-3 beta- ( $4^{\prime}$-iodophenyl)tropane (beta-CIT) with selective affinity to dopamine or serotonin transporters in rat forebrain. J Med Chem 39: $543-548$.

Neumeyer JL, Wang SY, Milius RA, Baldwin RM, Zea-Ponce Y, Hoffer PB et al (1991). [ $\left.{ }^{123} \mathrm{I}\right]-2$ beta-carbomethoxy-3 beta-(4iodophenyl)tropane: high-affinity SPECT radiotracer of monoamine reuptake sites in brain. J Med Chem 34: 3144-3146.

NICE (2004). Clinical Guideline 23. Depression: Management of Depression in Primary and Secondary Care. December 2004 In: National Institute for Clinical Excellence: London. pp 1-63.

O'Brien PC, Fleming TR (1979). A multiple testing procedure for clinical trials. Biometrics 35: 549-556.

Owens MJ, Krulewicz S, Simon JS, Sheehan DV, Thase ME, Carpenter DJ et al (2008). Estimates of serotonin and norepinephrine transporter inhibition in depressed patients treated with paroxetine or venlafaxine. Neuropsychopharmacology Neuropsychopharmacology advance online publication, 16 April 2008; doi:10.1038/npp.2008.47.

Parsey RV, Kent JM, Oquendo MA, Richards MC, Pratap M, Cooper TB et al (2006). Acute occupancy of brain serotonin transporter by sertraline as measured by $\left[{ }^{11} \mathrm{C}\right] \mathrm{DASB}$ and positron emission tomography. Biol Psychiatry 59: 821-828. 
Pirker W, Asenbaum S, Hauk M, Kandlhofer S, Tauscher J, Willeit $M$ et al (2000). Imaging serotonin and dopamine transporters with $\left[{ }^{123} \mathrm{I}\right] \beta$-CIT SPECT: binding kinetics and effects of normal aging. J Nucl Med 41: 36-44.

Quitkin FM, Petkova E, McGrath PJ, Taylor B, Beasley C, Stewart J et al (2003). When should a trial of fluoxetine for major depression be declared failed? Am J Psychiatry 160: 734-740.

Rudolph RL, Fabre LF, Feighner JP, Rickels K, Entsuah R, Derivan AT (1998). A randomized, placebo-controlled, dose-response trial of venlafaxine hydrochloride in the treatment of major depression. J Clin Psychiatry 59: 116-122.

Ruhe HG, Dekker JJ, Peen J, Holman R, de Jonghe F (2005). Clinical use of the Hamilton Depression Rating Scale: is increased efficiency possible? A post hoc comparison of Hamilton Depression Rating Scale, Maier and Bech subscales, Clinical Global Impression, and Symptom Checklist-90 scores. Compr Psychiatry 46: 417-427.

Ruhe HG, Huyser J, Swinkels JA, Schene AH (2006). Dose escalation for insufficient response to standard dose selective serotonin reuptake inhibitors in major depressive disorder: systematic review. Br J Psychiatry 189: 309-316.

Rush AJ, Gullion CM, Basco MR, Jarrett RB, Trivedi MH (1996). The Inventory of Depressive Symptomatology (IDS): psychometric properties. Psychol Med 26: 477-486.

Rush AJ, Trivedi MH, Wisniewski SR, Stewart JW, Nierenberg AA, Thase ME et al (2006). Bupropion-SR, sertraline, or venlafaxineXR after failure of SSRIs for depression. $N$ Engl J Med 354: 1231-1242.

Saunders K, Simon G, Bush T, Grothaus L (1998). Assessing the feasibility of using computerized pharmacy refill data to monitor antidepressant treatment on a population basis: a comparison of automated and self-report data. J Clin Epidemiol 51: 883-890.

Schweizer E, Rickels K, Amsterdam JD, Fox I, Puzzuoli G, Weise C (1990). What constitutes an adequate antidepressant trial for fluoxetine? J Clin Psychiatry 51: 8-11.

Schweizer E, Rynn M, Mandos LA, DeMartinis N, Garcia-Espana F, Rickels K (2001). The antidepressant effect of sertraline is not enhanced by dose titration: results from an outpatient clinical trial. Int Clin Psychopharmacol 16: 137-143.

Suhara T, Takano A, Sudo Y, Ichimiya T, Inoue M, Yasuno F et al (2003). High levels of serotonin transporter occupancy with lowdose clomipramine in comparative occupancy study with fluvoxamine using positron emission tomography. Arch Gen Psychiatry 60: 386-391.

Takano A, Suzuki K, Kosaka J, Ota M, Nozaki S, Ikoma Y et al (2006). A dose-finding study of duloxetine based on serotonin transporter occupancy. Psychopharmacology (Berl) 185: 395-399.

Thase ME, Shelton RC, Khan A (2006). Treatment with venlafaxine extended release after SSRI nonresponse or intolerance: a randomized comparison of standard- and higher-dosing strategies. J Clin Psychopharmacol 26: 250-258.

Trivedi MH, Fava M, Wisniewski SR, Thase ME, Quitkin F, Warden D et al (2006a). Medication augmentation after the failure of SSRIs for depression. N Engl J Med 354: 1243-1252.

Trivedi MH, Rush AJ, Wisniewski SR, Nierenberg AA, Warden D, Ritz L et al (2006b). Evaluation of outcomes with citalopram for depression using measurement-based care in $\mathrm{STAR}^{\star} \mathrm{D}$ : implications for clinical practice. Am J Psychiatry 163: 28-40.

van Dyck $\mathrm{CH}$, Malison RT, Seibyl JP, Laruelle M, Klumpp H, Zoghbi SS et al (2000). Age-related decline in central serotonin transporter availability with $\left[{ }^{123} \mathrm{I}\right] \beta$-CIT SPECT. Neurobiol Aging 21: 497-501.

Voineskos AN, Wilson AA, Boovariwala A, Sagrati S, Houle S, Rusjan $P$ et al (2007). Serotonin transporter occupancy of highdose selective serotonin reuptake inhibitors during major depressive disorder measured with $\left[{ }^{11} \mathrm{C}\right] \mathrm{DASB}$ positron emission tomography. Psychopharmacology (Berl) 193: 539-545.

Zitterl W, Aigner M, Stompe T, Zitterl-Eglseer K, Gutierrez-Lobos K, Wenzel $\mathrm{T}$ et al (2008). Changes in thalamus-hypothalamus serotonin transporter availability during clomipramine administration in patients with obsessive-compulsive disorder. Neuropsychopharmacology advance online publication, 19 March 2008; doi:10.1038/npp.2008.35.

Supplementary Information accompanies the paper on the Neuropsychopharmacology website (http://www.nature.com/npp) 